\title{
Aortic valve replacement with combined myocardial
} revascularisation

\author{
M JONES, P M SCHOFIELD, N H BROOKS, J F DARK, H MOUSSALLI, \\ A K DEIRANIYA, R A M LAWSON, A N RAHMAN \\ From the Regional Cardiac Centre, Wythenshawe Hospital, Manchester
}

SUMMARY Early and late outcome was studied in 630 patients who underwent aortic valve replacement between 1974 and 1982 . Group 1 (506 patients) did not have important coronary artery disease, group 2 (69 patients) had coronary artery disease and underwent coronary artery bypass grafting, and group 3 ( 55 patients) had coronary artery disease but did not undergo myocardial revascularisation. Early mortality (within 30 days of operation) was significantly lower for group $1(6 \%)$ than for group $2(13 \%)$ and for group $3(16 \%)$. Operative mortality in all three groups was lower in patients operated on more recently. The three year survival of patients in group $1(83 \%)$ was significantly higher than that of patients in group $3(62 \%)$ but not than that of patients in group $2(76 \%)$.

The findings of this study suggest that the presence of coronary artery disease increases the risk of aortic valve replacement whether or not coronary artery grafting is performed. Myocardial revascularisation, however, seems to return patients with aortic valve and coronary artery disease to a survival curve similar to that of patients with isolated aortic valve disease.

Since 1960 when Harken et al first performed intracardiac aortic valve replacement using a caged ball prosthesis in the subcoronary position, ${ }^{1}$ isolated aortic valve replacement has become well established and is routinely practised both for the relief of symptoms and to improve prognosis. The role of additional coronary artery bypass grafting in patients found to have coronary artery disease is, however, less certain. A review of the results of combined aortic valve replacement and coronary artery grafting in several centres shows more variable early mortality than that seen after isolated aortic valve replacement. $^{23}$

There are several important questions to consider in the management of patients with aortic valve disease. Firstly, in patients who have clinical evidence of important aortic valve dysfunction we need to define which group of patients should undergo coronary angiography at the time of cardiac catheterisation. The second question is the definition of the group of patients who should undergo combined valve replacement and coronary bypass surgery. The mere demonstration of coronary artery disease does not necessarily indicate surgical treatment. Although coronary artery grafting in patients

Requests for reprints to Dr P M Schofield, Regional Cardiac Unit, Papworth Hospital, Papworth Everard, Cambridgshire CB3 8RE.

Accepted for publication 6 March 1989 with coronary artery disease is a good treatment for symptoms, it improves long term survival in only some patients. ${ }^{4-6}$ It may be that only in those patients with coronary artery disease of similar severity to that in patients in whom long term survival is improved will bypass grafting improve long term survival. Thirdly, what is the best surgical approach in this group of patients? Myocardial protection is made difficult both by the mass of ventricular muscle at risk during aortic cross clamping and by the presence of obstructive coronary arterial lesions. The combination of aortic valve surgery and coronary artery surgery should only be performed together if mortality and morbidity are low and there is a demonstrable long term improvement in symptoms and/or survival.

Most of these questions can only be investigated by the analysis of uncontrolled retrospective data. We have studied some of these questions in patients who had combined aortic valve disease and coronary artery disease. The place of surgery for isolated aortic valve disease is already well defined.

\section{Patients and methods}

\section{PATIENTS}

We reviewed the records of the 630 patients who underwent aortic valve replacement between January 
1974 and December 1982 at the Regional Cardiac Centre, Wythenshawe Hospital. The patients did not have important dysfunction of the other heart valves. Coronary arteriography was performed on 571 $(91 \%)$ patients and 125 patients were found to have important coronary artery disease ${ }^{4}(>50 \%$ reduction of intraluminal diameter of a major coronary artery).

Three groups of patients were identified. Group 1 consisted of 506 patients who had aortic valve disease but no evidence of important coronary artery disease. Group 2 consisted of 69 patients who had aortic valve disease and coronary artery disease and who underwent coronary artery surgery. The remaining 55 patients (group 3) had combined aortic valve disease and coronary artery disease, but did not undergo coronary artery bypass grafting.

On the basis of clinical findings and catheterisation data, patients were categorised as having aortic stenosis (peak systolic pressure gradient $\geqslant 50$ $\mathrm{mm} \mathrm{Hg}$ ), aortic incompetence (greater than $2 / 4$ as assessed from the aortogram by two experienced observers), or mixed aortic valve disease. Left ventricular function was assessed from the left ventricular angiogram by two experienced observers who estimated the left ventricular ejection fraction as poor $(<30 \%)$, moderate $(30-70 \%)$, or good $(>70 \%)$. The angiograms of all patients who underwent coronary arteriography were reviewed by at least two experienced observers.

\section{OPERATIVE TECHNIQUE}

Between 1974 and 1982, the period of this review, operative technique has changed. Aortic valve replacement is performed under standard cardiopulmonary bypass at moderate systemic hypothermia $\left(28^{\circ} \mathrm{C}\right)$. Before the widespread use of cardioplegia, the aorta was cross clamped and the heart was cooled topically by the technique described by Shumway $e t$ $a l^{7}$; a left ventricular vent was routinely used. If additional coronary artery grafting was carried out, distal anastomoses were constructed after valve replacement with the heart fibrillating, and the proximal anastomoses with the heart beating.

Currently, the aortic valve is replaced under cardioplegic arrest. For isolated valve replacement additional topical cooling is maintained by a cooling jacket around the heart. In combined aortic valve and saphenous vein bypass surgery, slush is applied to the arrested heart and the valve is excised. The distal anastomoses are then constructed, and finally the valve is replaced and proximal anastomoses are completed after closure of the aorta, with the heart beating.

A mechanical valve was used for $90 \%$ of patients in group $1,88 \%$ of patients in group 2 , and $89 \%$ of patients in group 3. The remaining patients had
Table 1 Clinical details of patients in group 1, group 2, and group 3

\begin{tabular}{lclc}
\hline & $\begin{array}{l}\text { Group 1 } \\
(n=506)\end{array}$ & $\begin{array}{l}\text { Group 2 } \\
(n=69)\end{array}$ & $\begin{array}{l}\text { Group 3 } \\
(n=55)\end{array}$ \\
\hline $\begin{array}{l}\text { Mean (SD) age (years) } \\
\text { Valve lesion: }\end{array}$ & $51(13)^{\star}$ & $58(7)$ & $61(7)$ \\
$\quad$ Aortic stenosis & $171(34 \%)$ & $18(26 \%)$ & $23(42 \%)$ \\
Aortic incompetence & $218(43 \%)$ & $28(41 \%)$ & $19(35 \%)$ \\
$\quad$ Mixed & $117(23 \%)$ & $23(33 \%)$ & $13(23 \%)$ \\
NYHA: & $233(46 \%)$ & $14(20 \%)^{\star \star}$ & $27(49 \%)$ \\
I & $46(9 \%)$ & $11(16 \%)^{\star \star}$ & $5(9 \%)$ \\
II & $207(41 \%)$ & $40(58 \%)^{\star \star}$ & $21(38 \%)$ \\
III & $20(4 \%)$ & $4(6 \%)^{\star \star}$ & $2(4 \%)$ \\
IV & $233(46 \%)$ & $55(80 \%)^{\star \star}$ & $27(49 \%)$ \\
Angina: & $273(54 \%)$ & $14(20 \%)^{\star \star}$ & $28(51 \%)$ \\
Yes & &
\end{tabular}

Group 1, patients who underwent aortic valve replacement; group 2, patients who underwent aortic valve replacement and coronary artery surgery; group 3, patients with coronary artery disease who underwent aortic valve replacement only.

* Significantly different from group 2 and group $3(p<0.01)$.

$\star \star$ Significantly different from group 1 and group $3(p<0.01)$.

tissue valves. All patients with mechanical valves were on long term anticoagulant treatment, whereas anticoagulants were stopped after three months in patients with tissue valves.

\section{STATISTICAL ANALYSIS}

We examined group differences by a one way analysis of variance and compared proportions by the $\chi^{2}$ test.

Actuarial survival curves were calculated by standard life table analysis techniques. ${ }^{8}$

\section{Results}

Table 1 shows the clinical details and table 2 the results of cardiac catheterisation. The patients who had important coronary artery disease (groups 2 and 3 ) were significantly older $(p<0.01)$ than patients in

Table 2 Coronary angiographic findings and left ventricular function in group 2 and group 3

$\begin{array}{ll}\text { Group 2† } & \text { Group 3† } \\ (n=69) & (n=55)\end{array}$

Coronary artery disease:
1 vessel
Left anterior descending
Circumflex
Right
2 vessel
3 vessel
Left main stem stenosis
Mean no. grafts/patient
Ejection fraction:
Poor $(<30 \%)$
Moderate $(30-70 \%)$
Good $(>70 \%)$

*Significantly different from group $3(p<0.01)$.

+ See footnote to table 1 for definitions. 
Table 3 Early mortality of patients in group 1, group 2, and group 3 between 1974 and 1978 and between 1979 and 1982

\begin{tabular}{llll}
\hline & $\begin{array}{c}\text { Group 1† } \\
(n=506)\end{array}$ & $\begin{array}{l}\text { Group 2+ } \\
(n=69)\end{array}$ & $\begin{array}{l}\text { Group 3† } \\
(n=55)\end{array}$ \\
\hline $\begin{array}{llll}\text { 1974-1978: } \\
\text { No of patients undergoing } \\
\text { operation }\end{array}$ & 208 & 19 & 16 \\
$\begin{array}{c}\text { Early mortality } \\
\text { 1979-1982: }\end{array}$ & $23(11 \%)$ & $5(26 \%)$ & $4(25 \%)$ \\
No of patients undergoing & & & \\
operation & 298 & 50 & 39 \\
$\begin{array}{c}\text { Early mortality } \\
\text { Overall early mortality }\end{array}$ & $9(3 \%)$ & $4(8 \%)$ & $5(13 \%)$ \\
\hline
\end{tabular}

*Significantly different from group 2 and group $3(p<0.01$ ).

tSee footnote to table 1 for definitions.

group 1. There was no significant difference in the nature of the aortic valve lesion between the three groups of patients. More patients in group 2 had angina before operation than groups 1 and 3 $(\mathbf{p}<0.01)$. Twenty six per cent of patients who experienced angina had important coronary artery disease compared with $13 \%$ of those who did not have angina.

Of the patients who had coronary artery disease, those who underwent coronary artery bypass grafting (group 2) had more severe coronary disease $(\mathrm{p}<0.01)$ and were in a worse functional state before operation $(p<0.01)$ than those who did not undergo coronary artery surgery (group 3 ). There was no significant difference, however, in preoperative left ventricular function between group 2 and group 3. Preoperative left ventricular function in the patients with coronary artery disease was not significantly different from that of patients in group $1 ; 23 \%$ poor, $44 \%$ moderate, and $33 \%$ good (table 2 ). The overall early (within 30 days of operation) mortality for the three groups of patients was $6 \%$ for group 1, 13\% for group 2, and 16\% for group 3. Early mortality was significantly lower $(p<0.01)$ in group 1 than in group 2 and group 3. Table 3 shows the reduction in operative mortality of patients operated on more recently. The overall early mortality for patients who had cardioplegia for myocardial protection was $6.6 \%(4 \cdot 2 \%(18 / 428)$ in group 1 ,

Table 4 Proportion of patients who required haemodynamic support postoperatively and incidence of perioperative myocardial infarction in group 2 and group 3

Group 2† Group 3†

$(n=69) \quad(n=55)$

\begin{tabular}{lll} 
Haemodynamic support postoperatively & $26 \%$ & $27 \%$ \\
Perioperative myocardial infarction & $17 \%$ & $15 \%$ \\
\hline
\end{tabular}

*Development of new $Q$ wave > $0.04 \mathrm{~s}$.

tSee footnote to table 1 for definitions.
$13.2 \%(9 / 68)$ in group 2 , and $17.6 \%(9 / 51)$ in group 3). The overall early mortality for patients who did not receive cardioplegia was $16.9 \%$ (17.9\% (14/78) in group 1, 0\% (0/1) in group 2, and $0 \%(0 / 4)$ in group 3).

Seven of the nine early deaths in group 2 were caused by a low cardiac output and failure to wean from cardiopulmonary bypass. Of the remaining two deaths one was caused by pancreatitis in relation to a low cardiac output state and one occurred ten days after operation in a man who had undergone aortic valve replacement and a single right coronary artery graft, and at necropsy the artery was found to be blocked.

There were nine early deaths in group 3 . Seven of these were caused by low cardiac output and failure to wean from cardiopulmonary bypass. One occurred at 21 days in a patient who had persistent infection after three valve replacements for infective endocarditis, and the other was a man who underwent emergency surgery and died 21 days after operation of myocardial failure. There was only one early death in the 35 patients in group 3 who had single vessel disease while eight deaths occurred in the 20 patients who had two (or three) vessel disease or left main stem stenosis.

After operation, some patients required either inotropic infusions or placement of an intra-aortic

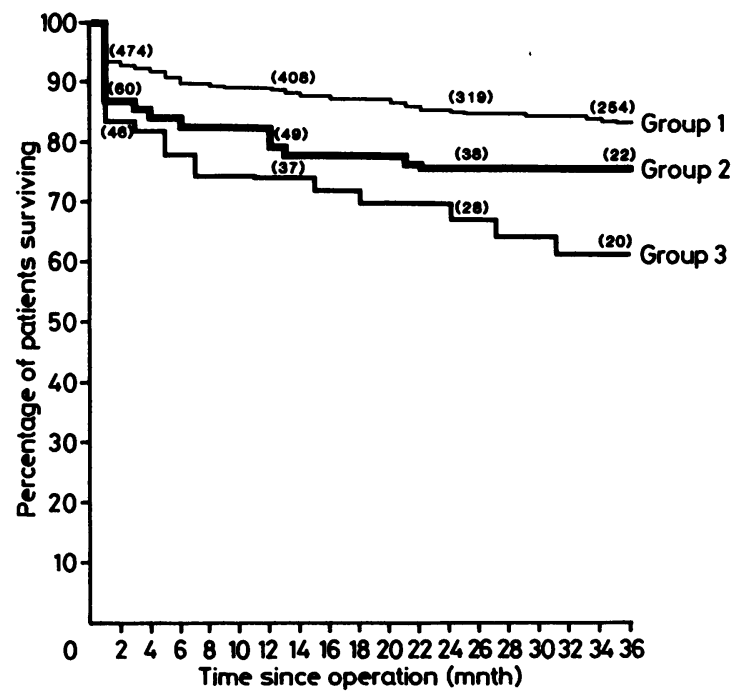

Fig 1 Actuarial survival curve for the three groups of patients. Group 1, patients who underwent aortic valve replacement; group 2, patients who underwent aortic valve replacement and coronary artery surgery; group 3 , patients with coronary artery disease, who underwent aortic valve replacement only. Figures in parentheses indicate the number of patients in each group entering that particular follow up period. 


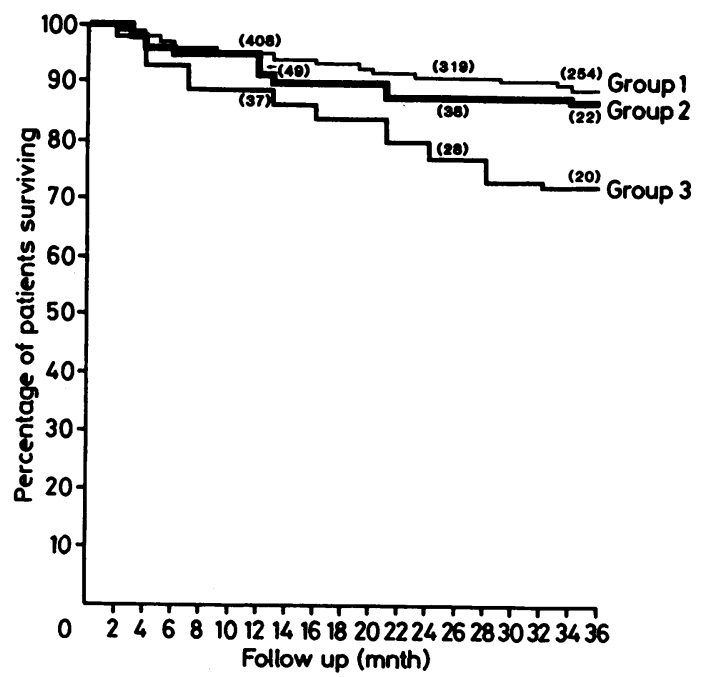

Fig 2 Actuarial survival curve for the patients who had survived beyond 30 days after operation in each of the three groups (see legend to figure 1).

balloon pump (table 4). Perioperative myocardial infarction was defined as the development of a new $Q$ wave of at least $0.04 \mathrm{~s}$ in the postoperative electrocardiogram. This was found in $17 \%$ of operative survivors in group 2 and $15 \%$ of operative survivors in group 3. In group $1,4 \%$ of operative survivors had evidence of perioperative myocardial infarction.

Figure 1 shows the survival curves for the three groups of patients. Patients in group 1 had a significantly better outcome than patients in group 3 (p $=0.001$ ), but not than that of patients in group 2 . Of the patients with coronary artery disease, the patients who had undergone coronary artery bypass grafting (group 2) had a higher three year survival ( $76 \%$ ) than those who did not undergo coronary artery surgery (group 3, 62\%), but the difference was not statistically significant. The survival curves for the patients who had survived for more than 30 days after operation were also analysed (fig 2). Again, the outcome of patients in group 1 was better than that of patients in group $3(p=0.02)$ but not than that of patients in group 2 . Although patients with coronary artery disease who underwent coronary artery surgery did better than those who did not, the difference did not quite reach statistical significance. Figures 1 and 2 show that after the initial difference in early mortality, the survival curves for group 1 and group 2 are parallel. The curve for group 3, however, falls away from these two curves with time, indicating a worse long term outcome.

At the most recent follow up assessment, $86 \%$ of survivors in group 2 were in New York Heart Association class $\mathrm{I}, 8 \%$ in class $\mathrm{II}$, and $6 \%$ in class
III. In group 3 , the proportions were $82 \%, 12 \%$, and $6 \%$ respectively. There have been six late ( $>30$ days after operation) deaths in group 2: two of these were attributable to cardiac failure, two to malignant disease, and one each to myocardial infarction and cerebrovascular accident. In group 3, there have been nine late deaths: four caused by myocardial infarction, three by cardiac failure, and one each by cerebrovascular accident and infective endocarditis.

\section{Discussion}

Many centres perform adjunctive coronary artery grafting at the time of valve replacement in patients with combined aortic valve disease and coronary artery disease. The validity of this approach is based firstly on the principle that correction of two coexisting abnormalities should have an additive beneficial effect. ${ }^{9}$ Secondly, although hospital mortality I for aortic valve replacement tends to be higher in the presence of coronary artery disease ${ }^{910}$ it is probably not affected by the additional procedure of coronary artery grafting. Bonow et al, however, concluded that coronary artery bypass grafting at the time of valve replacement is not advantageous as a near-routine procedure for patients with combined important aortic valve and coronary artery disease. ${ }^{11}$

An evaluation of the place of coronary artery grafting in patients with combined aortic valve dysfunction and coronary artery disease should be based on age and sex matched populations of patients with similar aetiology and severity of aortic valve disease, with a similar degree of coronary artery disease. The two groups of patients should be operated upon during the same period of time, and the analysis should include early and late survival, symptomatic outcome, and the incidence of late complications. But such a study has not been and perhaps never will be performed.

The advisability of routine coronary arteriography at the time of cardiac catheterisation remains controversial. Apart from defining obstructive lesions in the coronary arterial tree it is also valuable in defining anatomy of the left main stem. It has been suggested, however, that routine angiography may not be necessary in patients who do not have angina ${ }^{12}$ and it has been proposed that valve replacement may be performed safely without this preoperative investigation. ${ }^{13}$ Aortic stenosis was initially thought to confer some protection against the development of coronary artery disease. ${ }^{14}$ Since the introduction of coronary angiography, the reported incidence of coronary artery disease in patients with aortic valve disease has varied between $20 \%$ and $60 \% .{ }^{15-17}$ Some have suggested that coronary artery disease is only found in patients who have angina. ${ }^{18}$ Ramsdale et al, 
however, in a study of patients with valvar heart disease undergoing coronary angiography found that $13 \%$ of patients with aortic valve disease and no angina had coronary artery disease..$^{20}$ The limitations of angina in predicting the presence of coronary artery disease in patients with aortic valve disease was also found by Coleman and Soloff. ${ }^{21}$ In the present series, $26 \%$ of patients who experienced angina had important coronary artery disease, compared with $13 \%$ of those who did not have angina. It has been shown that the unexpected finding of important coronary artery disease at the time of aortic valve replacement worsens the operative outcome. ${ }^{22}$

The importance of preoperative diagnosis of coronary artery disease has been suggested in studies that examine both the influence of coronary artery disease and coronary artery surgery on the morbidity and mortality of aortic valve replacement. ${ }^{910}$ The present study has shown that the presence of coronary artery disease increases the risk when patients have aortic valve replacement, whether or not coronary artery bypass grafting is performed. Czer et al have also recently shown that coexistent coronary disease reduces early survival after aortic valve replacement. ${ }^{23}$ In these patients, at operation and during aortic cross clamping, the heart is subject to limited distribution of either cardioplegia fluid as a protective agent or blood as an energy substrate. Although some of the patients in the present series had important coronary artery disease, they did not undergo bypass surgery. The reason for this was not usually clear; it did not seem to be related to the size of the vessel or the site of the lesion. It was probably because the value of routine myocardial revascularisation was not appreciated when the patients underwent surgery. It is also possible that patients with more widespread disease were more likely to undergo bypass surgery.

In a recent report Scott $e t$ al analysed the influence of several factors on operative mortality by univariate and multivariate analysis. ${ }^{9}$ In the whole group, the presence of coronary artery disease did have an adverse influence on mortality, although the concomitant procedure of coronary artery surgery had no significant effect on operative mortality. Age was cited as an independent determinant of operative mortality in the entire group, although it was not stated whether the patients with coronary artery disease differed in age from those without coronary artery disease. Czer et al have recently shown that complete revascularisation does not increase operative risk when coronary artery disease is present. ${ }^{23}$ In this series, the age difference between patients with and those without coronary artery disease was significant and may account for some of the difference in early mortality. Data supporting coronary artery disease as a risk factor are evident in reports by Loop et al, ${ }^{2}$ Linhart et $a l,{ }^{24}$ and Cooley et al. ${ }^{25}$ Nunley and co-workers considered the problems of differing characteristics of patient subgroups through relative survival computations for age and sex variation. ${ }^{3}$ Between 1976 and 1981 they reported an operative mortality of only $5 \%$, which is similar to that reported for isolated aortic valve replacement. Their results, together with the favourable long term outcome for the combined operation group led to the recommendation of combined aortic valve and coronary artery surgery.

Factors such as the differing severity of coronary artery disease and the variation in preoperative functional state made the comparison of different patient subgroups in the present study difficult. Although patients who received cardioplegia had a lower early mortality than those who did not, this did not explain the differences seen between the three groups. However, of the patients with coronary artery disease, those who underwent coronary artery surgery had more severe coronary disease and a worse functional state before operation than those who did not undergo myocardial revascularisation. It is noteworthy that only $11 \%$ of the early deaths in the patients with important coronary artery disease who did not undergo bypass surgery occurred in those with single vessel disease, although they formed $64 \%$ of the group. Both groups of patients with coronary artery disease had similar requirements for inotropic support after operation and similar rates of perioperative myocardial infarction. It is probable that the inotropic requirement reflects important myocardial damage more accurately than electrocardiographic changes, which do not correlate well with more sensitive indices for myocardial infarction. ${ }^{26} 27$

The optimal operative management of patients undergoing aortic valve replacement in the presence of coronary artery disease remains uncertain. This is important since operative mortality is almost exclusively related to myocardial infarction, which is a direct reflection of myocardial protection. It has been suggested that distal obstructions of coronary arteries should be bypassed early in the procedure to allow protection of myocardium beyond the stenoses. ${ }^{26}$ Valve replacement and placement of distal coronary artery graft anastomoses during a single anoxic interval during cardioplegic arrest and topical hypothermia is a simpler procedure and this is associated with good results. ${ }^{928}$

In this series it is clear that the presence of coronary artery disease conferred a significant risk to surgery whether or not coronary artery grafting was performed. Furthermore, the presence of coronary artery disease that was not treated surgically had an adverse long term influence. The late deaths in 
patients with significant coronary artery disease who did not undergo revascularisation tended to be related to complications of coronary artery disease. This trend was seen in the report by Copeland et al, who also suggested that the concept of presenting a probability of survival for a large heterogeneous group of patients undergoing a procedure such as aortic valve replacement is of limited value. ${ }^{10}$ Nunley and colleagues, however, using a more complex statistical analysis suggested that performance of coronary artery surgery returns those patients with combined aortic valve and coronary artery disease to a "prognostic class" equivalent to individuals with only aortic valve disease, ${ }^{3}$ and supported their data by comparing survival curves with four other reported series. Revascularisation in patients with coexistent coronary artery disease seems to reduce the occurrence of late sudden death. ${ }^{23}$ In these patients impaired preoperative left ventricular function and advanced age reduced the late survival rates. ${ }^{29}$ The findings of the present study suggest that myocardial revascularisation returns patients with aortic valve and coronary artery disease to a prognostic "curve" similar to that of patients with isolated aortic valve disease.

We thank Mr E B Faragher for advice on statistics.

\section{References}

1 Harken DE, Soroff HS, Taylor WJ, Lefemine AA, Gupta SK, Lunzer S. Partial and complete prostheses in aortic insufficiency. $J$ Thorac Cardiovasc Surg 1960;40:744-62.

2 Loop FD, Phillips DF, Roy M, Taylor PC, Groves LK, Effler DB. Aortic valve replacement combined with myocardial revascularisation-late clinical results and survival of surgically treated aortic valve patients with and without coronary artery disease. Circulation 1977;55:169-73.

3 Nunley DL, Grunkemeier GL, Starr A. Aortic valve replacement with coronary bypass grafting. $J$ Thorac Cardiovasc Surg 1983;85:705-11.

4 European Coronary Surgery Study Group. Prospective randomised study of coronary artery bypass surgery in stable angina pectoris. Lancet 1980;ii:491-5.

5 The Veterans Administration Coronary Artery Bypass Surgery Cooperative Study Group. Eleven-year survival in the Veterans Administration randomised trial of coronary bypass surgery for stable angina. $N$ Engl J Med 1984;311:1333-9.

6 CASS principal investigators and their associates. Coronary Artery Surgery Study: a randomised trial of coronary artery bypass surgery. Survival data. Circulation 1983;68:939-50.

7 Shumway NE, Lower RR, Stofer RC. Selective hypothermia of the heart in anoxic cardiac arrest. Surg Gynecol Obstet 1959;109:750-4.
8 Underwood CJ, Faragher EB, Charlesworth DC. The uses and abuses of life-table methods in vascular surgery. Br J Surg 1984;71:495-8.

9 Scott WC, Miller DK, Haverich A, et al. Determinants of operative mortality for patients undergoing aortic valve replacement. Discriminant analysis of 1,479 operations. J Thorac Cardiovasc Surg 1985;89: 400-13.

10 Copeland JG, Griepp RB, Stinson MD, Shumway NE. Long term follow up after isolated aortic valve replacement. J Thorac Cardiovasc Surg 1977;74: 875-89.

11 Bonow RO, Kent KM, Rosing DR, et al. Aortic valve replacement without myocardial revascularization in patients with combined aortic valvular and coronary artery disease. Circulation 1981;63:243-51.

12 Bonchek LI, Anderson RP, Rosch J. Should coronary artery arteriography be performed routinely before valve replacement? $A m \quad J$ Cardiol 1973;31: 462-6.

13 St John Sutton MG, St John Sutton M, Oldershaw P, et al. Valve replacement without preoperative cardiac catheterization. $N$ Engl J Med 1981;305:1233-8.

14 Nakib A, Lillehei CW, Edwards JE. The degree of coronary atherosclerosis in aortic valvular disease. Arch Pathol 1965;80:517-20.

15 Basta LL, Raines D, Najiar S, Kioschos JM. Clinical, haemodynamic, and coronary angiographic correlates of angina pectoris in patients with severe aortic valve disease. Br Heart J 1975;37:150-7.

16 Berndt TB, Hancock EW, Shumway NE, Harrison DC. Aortic valve replacement with and without coronary artery bypass surgery. Circulation 1974;50:967-71.

17 Parker DJ, Jacob T, Seabra-Gomes RS. Importance of coronary artery disease in surgery of aortic valve disease [Abstract]. Br Heart J 1974;36:1039.

18 Anderson RP, Bonchek LI, Wood JA, Chapman RP, Starr A. The safety of combined aortic valve replacement and coronary bypass grafting. Ann Thorac Surg 1973;15:249-55.

19 Exadactylos N, Sugrue DD, Oakley CM. Prevalence of coronary artery disease in patients with isolated aortic valve stenosis. Br Heart J 1984;51:121-4.

20 Ramsdale DR, Bennett DH, Bray CL, Ward C, Beton DC, Faragher EB. Coronary arteriography prior to valve replacement. Eur Heart J 1981;2:83-6.

21 Coleman EH, Soloff LA. Incidence of significant coronary artery disease in rheumatic valvular heart disease. Am J Cardiol 1970;25:401-4.

22 Flemma RJ, Johnson WD, Lepley D, Auer JE, Tector AJ, Blitz J. Simultaneous valve replacement and aorta-to-coronary saphenous vein bypass. Ann Thorac Surg 1971;12:163-70.

23 Czer LS, Gray RJ, Stewart ME, De Robertis M, Chaux A, Matloff JM. Reduction in sudden late death by concomitant revascularization with aortic valve replacement. J Thorac Cardiovasc Surg 1988;95: $390-401$.

24 Linhart JW, de la Torre A, Ramsey HW, Wheat MW. The significance of coronary artery disease in aortic valve replacement. $J$ Thorac Cardiovasc Surg 1968; 55:811-9. 
25 Cooley DA, Dawson JT, Hallman GL, et al. Aortocoronary saphenous vein bypass. Results in 1,492 patients, with particular reference to patients with complicating features. Ann Thorac Surg 1973;17: 380-90.

26 Macmanus Q, Grunkemeier G, Lambert L, Dietl C, Starr A. Aortic valve replacement and aorta-coronary bypass surgery. J Thorac Cardiovasc Surg 1978; 75:865-9.

27 McGregor CGA, MacLeod MD, Muir AL, Smith AF, Hannan WJ, Miller HC. Myocardial infarction related to valve replacement surgery. Br Heart $J$ 1984;51:612-7.

28 Richardson JV, Kouchoukos NT, Wright JO, Karp RB. Combined aortic valve replacement and myocardial revascularization: results in 220 patients. Circulation 1979;59:75-81.

29 Lytle BW, Cosgrove DM, Gill CC, et al. Aortic valve replacement combined with myocardial revascularization. Late results and determinants of risk for 471 in-hospital survivors. $J$ Thorac Cardiovasc Surg 1988;95:402-14. 